\title{
Platelet aggregability in relation to impaired consciousness after head injury
}

\author{
CH. J. VECHT, J. M. MINDERHOUD, AND C. TH. SMIT SIBINGA 1 \\ From the Department of Neurology and the Coagulation Laboratory, Department of Internal Medicine ${ }^{1}$, \\ University Hospital, Groningen, the Netherlands
}

SYNOPSIS ADP-induced platelet aggregation was studied for up to six weeks in 34 patients with head injuries. The patients were divided into three groups according to the degree of impaired $\infty$ consciousness assessed by a clinical coma scale, and change in platelet aggregation was related to $\vec{\circ}$ the coma score. Platelet aggregation was markedly reduced in all eight patients dying within $24 \stackrel{\circ}{\circ}$ hours of injury. All 17 patients who remained unconscious for four days or more showed decreased platelet aggregation up to nine days after admission, the most marked effect being on the second day. 을 Platelet function in this group returned to normal within 16 days. Nine patients with only slightly impaired consciousness also showed subnormal platelet aggregation during the first few days with a return to normal by the fourth day. Platelet counts remained within normal limits in all groups. We suggest that during coma following head injury brainstem dysfunction induces neurohumoral changes in the blood which are responsible for a decrease in platelet function.

Several recent reports (Goodnight et al, 1974; Preston et al, 1974), have described coagulation abnormalities in relation to head trauma. In these studies platelet counts were done but no attention was given to platelet function. Platelet abnormalities are found in other neurological diseases; after cerebrovascular accidents decreased platelet aggregation has been described (Danta, 1973), and multiple sclerosis is associated with enhanced platelet stickiness (Caspary et al, 1965). In Down's syndrome platelet serotonin (5HT) uptake is found to be decreased (Bayer and McCoy, 1974). Functional disorders of the neutrophil granulocyte (which in several aspects is similar to the blood platelet (Stormorken, 1969)) are found after brain damage, anoxia (Dodsworth and Harris, 1971), and head injury (Van Woerkom et al, 1973). During general anaesthesia impaired phagocytosis is recognized (Löfström and Schildt, 1974) and during operations impaired platelet aggregability, possibly caused by general anaesthesia, has been described (O'Brien et $a l, 1971)$. In these conditions the changes in platelet and leucocyte function seem to be related to the state of consciousness. Therefore we aimed to study platelet function after severe head injury, particularly in relation to the degree of impaired con-

Received for publication 16 June 1975 sciousness. Preliminary results have already be reported (Vecht and Smit Sibinga, 1974).

\section{Materials and Methods}

PATIENTS

Thirty-four patients with head injury who had been admitted to hospital within two hours after injury? (mostly traffic accidents) were studied. The patients were divided into three groups.

\section{Group I}

Eight patients with severe head injuries died within 24 hours after injury because of massive brain ${ }_{\circ}$ damage. This was confirmed by necropsy in five cases. Six patients had skull fractures (vault and/or $\frac{}{2}$ base). Six patients had fractures elsewhere (including three patients with femoral fractures). Shock was $N$ present in three patients before blood was drawn for platelet studies. Four patients had pulmonary స్ complications.

\section{Group II}

Seventeen severely injured patients with a closed head injury remained deeply unconscious for four $r_{7}$ days or more. Three of them were operated upon because of a subdural haematoma. Eleven patients $\vec{D}$ had fractured skulls (vault and/or base). Nine had융 
fractures elsewhere, of whom three had femoral fractures, and three patients were in shock on admission. Nine patients had pulmonary complications on admission. Three remained in a persistent vegetative state (Jennett and Plum, 1972). Four patients died between six weeks and six months after injury.

\section{Group III}

Nine patients sustained a moderate head injury with slightly impaired consciousness. In five, a fracture of the skull (vault and/or base) was present. Three patients had fractures elsewhere (no femoral fractures). One patient was in shock, and another patient had pulmonary complications on admission. All patients made a relatively fast and good recovery.

BLOOD SAMPLING AND PLATELET STUDIES

Blood was drawn immediately after admission and on each day thereafter during the first five days, at day 9 , and weekly up to the fifth or sixth week post-trauma, if the patient was still in hospital. Blood was collected mostly by venepuncture in plastic disposable syringes and was immediately mixed with 0.1 volume of $3.06 \%$ trisodium citrate dihydrate. Platelet-rich plasma was prepared in an Optima BHG 600 centrifuge at $250 \mathrm{~g}$ for 10 minutes. Platelet aggregation was performed using the Born technique (1962) at room temperature on a Vitatron UC 200 spectrophotometer connected with a Vitatron universal lin/log 300 recorder. Aggregation was induced by ADP in a final concentration of 0.75 $\mu \mathrm{g} / \mathrm{ml}$, and the maximum optical density (ODmax) loss and the rate of optical density change (the slope) were assessed. Also the ODmax after 10 minutes was measured.

Platelet counts were measured by a Coulter counter.

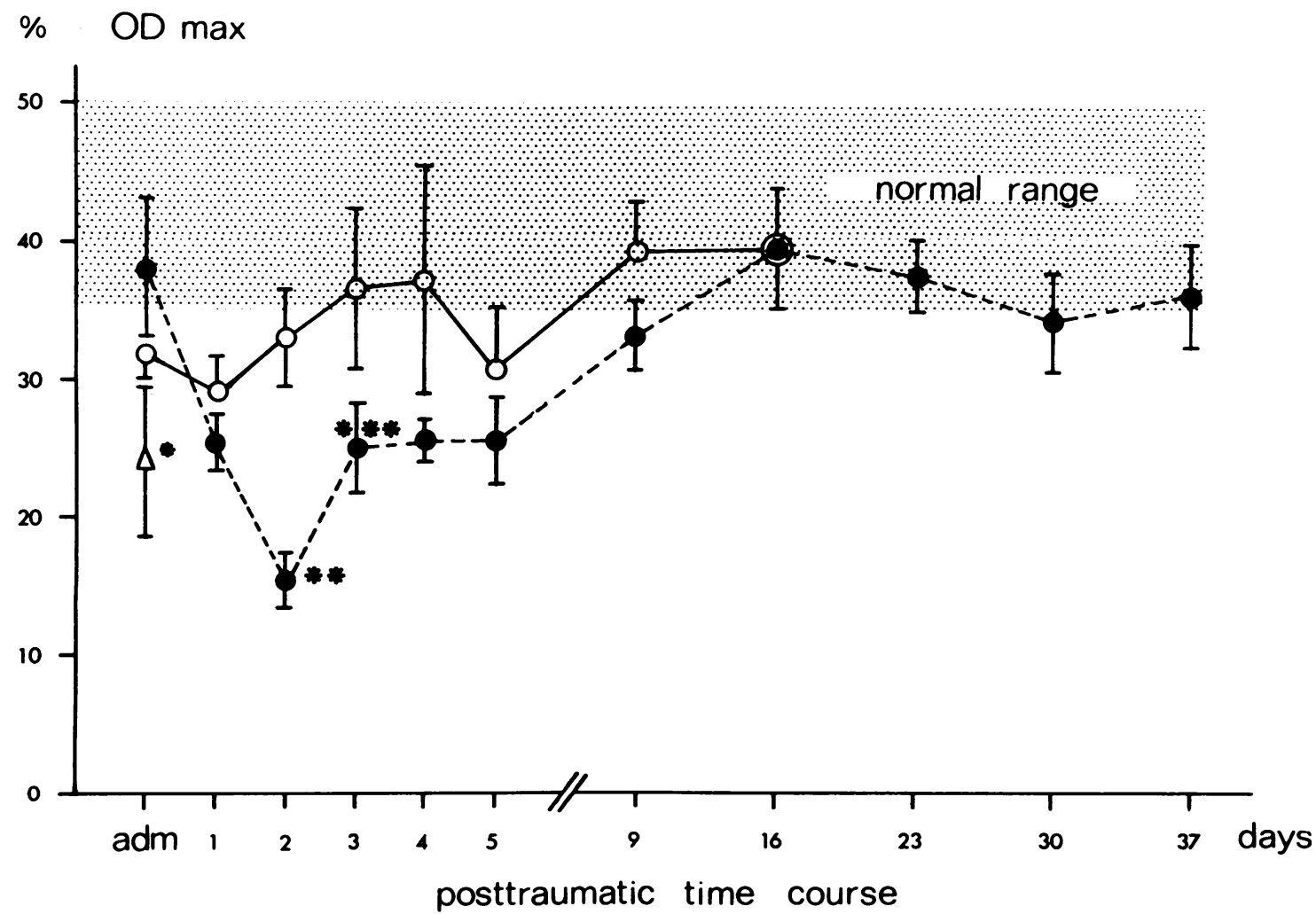

Fig 1 ODmax values (mean $\pm S E M$ ) of platelet aggregation curves of head injury patients during post-traumatic time course.

$\triangle$ group I; $\bigcirc$ group II; O group III.

* $(\mathrm{P}<0.05)$ : significantly different from severely injured patients. ${ }^{* *}(\mathrm{P}<0.001)$ and ${ }^{* * *}(\mathrm{P}<0.05)$ : significantly different from moderately injured patients. 


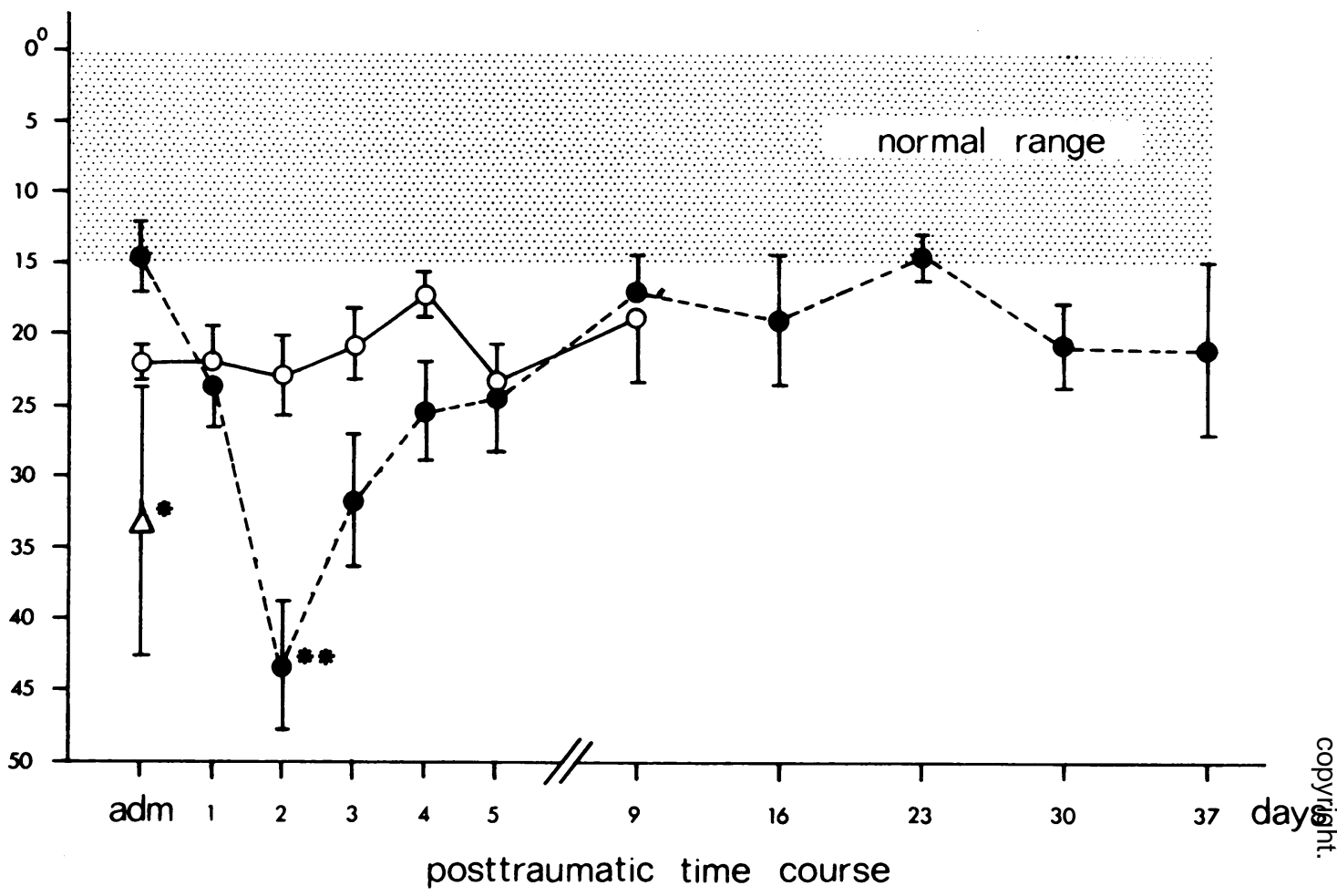

Fig 2 Slope values (mean $\pm S E M$ ) of platelet aggregation curves of head injury patients during post-traumatic time course.

$\triangle$ group I; $\bigcirc$ group II; $\bigcirc$ group III.

${ }^{*}(\mathrm{P}<0.05)$ : significantly different from severely injured patients. ${ }^{* *}(\mathrm{P}<0.005)$ : significantly different from moderately injured patients.

COMA SCALE

The state of consciousness of the patients was assessed by a clinical coma scale developed by Teasdale and Jennett (1974): the degree of coma is determined by the rate of $(a)$ eye opening ( 4 grades), (b) motor responsiveness (6 grades), and (c) verbal response ( 5 grades) of the patient by verbal demand and pain stimulus. The separate and total coma scores give a measure of the state of consciousness of the patient. Blood was drawn for platelet function studies at the same time that the state of consciousness was assessed.

The platelet aggregation data were correlated with the sum of the coma scores of the patients in groups II and III. Correlations were also sought between platelet aggregation data and motor responsiveness score, between platelet counts and total coma score, and between platelet counts and motor responsiveness. For statistical analysis Student's $t$ test for two means, linear regression and
Spearman's rank correlation coefficient, was carried out.

\section{Results}

GROUP I

The rapidly dying patients showed a remarkably $I$ decreased ODmax and flattening of the slope of the platelet aggregation curve on admission (figs 1 and $\tilde{N}$ 2).

Platelet counts were at the lower end of the normal range (fig 3).

GROUP II

In the severely injured patients, ODmax on admission was just normal and decreased considerably? thereafter with a minimum at day 2 . Around day 16 , 7 ODmax returned to normal (fig 1). The slope showed the same course (fig 2). Disaggregation phenomena were frequently seen. Platelet counts remained $\stackrel{\mathbb{Q}}{\varrho}$ 


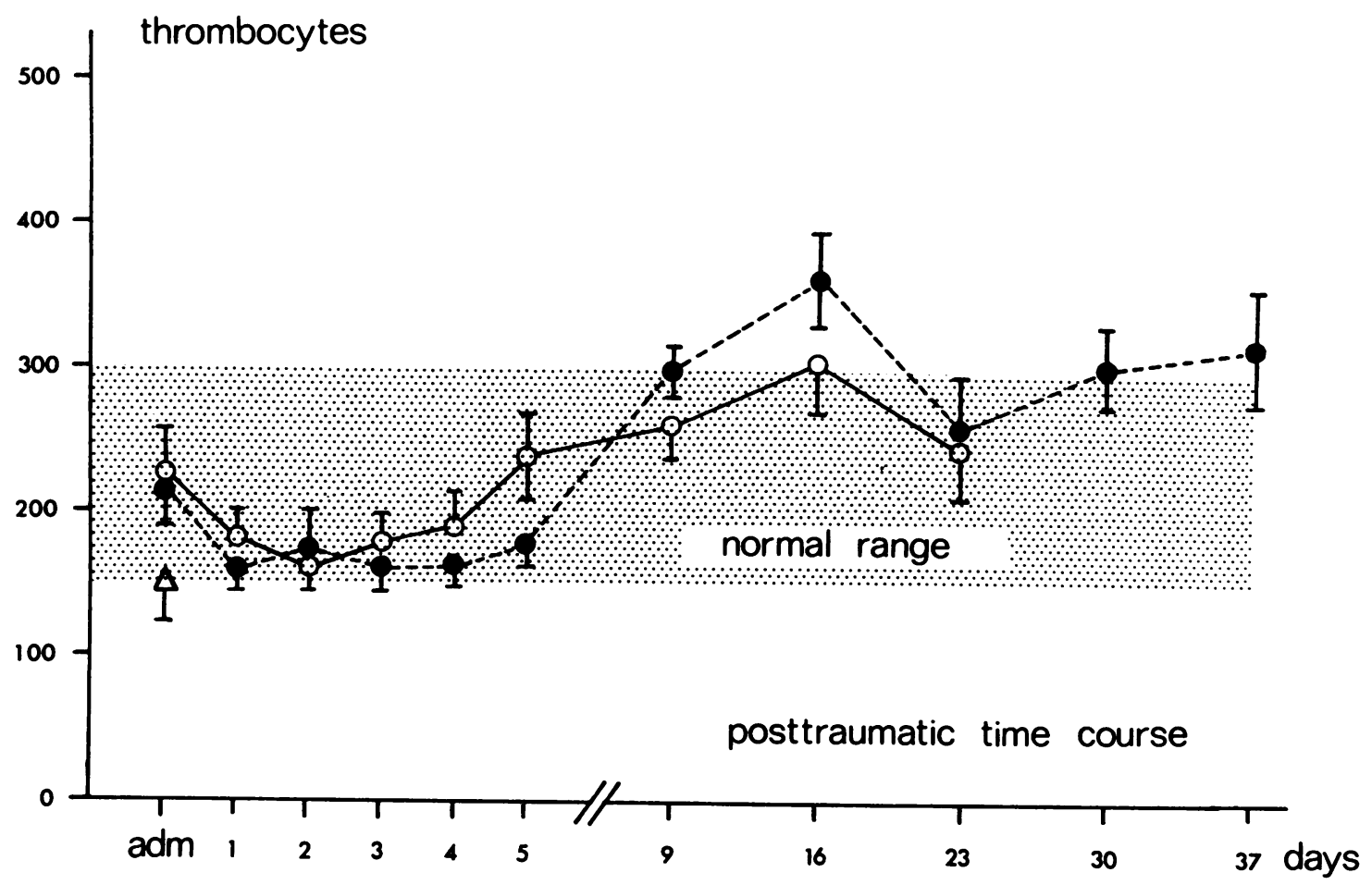

Fig 3 Platelet counts (mean \pm SEM) during post-traumatic time course.

$\triangle$ group I; group II: $\bigcirc$ group III.

within the normal ranges, although in the acute post-traumatic phase a tendency to borderline levels was noticed (fig 3).

\section{GROUP III}

The moderately injured patients showed a subnormal ODmax and slope on admission (figs 1 and 2). Compared with group II, these patients showed a less remarkably diminished platelet aggregability during the first days: a significantly less inhibited ODmax on days $2(P<0.001)$ and $3(P<0.05)$ and less flattening of the slope on day $2(\mathrm{P}<0.005)$. But, as in group II, disaggregation phenomena were frequently seen.

A significant correlation (Spearman's rank) was present between total coma score and ODmax on days 2,3 , and 4 (table I, fig 4): the greater the impairment of consciousness the greater was the diminution of platelet function. Furthermore, significant correlations were found between motor responsiveness score and ODmax values on days 2 , 3 , and 4 (table I). The flattening of the slope of the optical density did not show a significant correlation with the degree of impaired consciousness.

\begin{tabular}{|c|c|c|c|c|}
\hline \multirow{2}{*}{$\begin{array}{l}\text { Day } \\
\text { Admission }\end{array}$} & \multicolumn{2}{|c|}{$\begin{array}{l}\text { Total Coma } \\
\text { Score v } \\
\text { ODmax }\end{array}$} & \multicolumn{2}{|c|}{$\begin{array}{l}\text { Motor Responsiveness } \\
\text { Score v } \\
\text { ODmax }\end{array}$} \\
\hline & 0.26 & (9) & 0.21 & (9) \\
\hline & $0 \cdot 30$ & (18) & $0 \cdot 31$ & (18) \\
\hline 2 & $0.85^{* * *}$ & (15) & $0.81 * *$ & (15) \\
\hline 3 & $0.60^{*}$ & (16) & $0.68 * *$ & (16) \\
\hline 4 & $0.75^{* * *}$ & (14) & $0.67 *$ & (14) \\
\hline 5 & 0.19 & (16) & 0.29 & (16) \\
\hline 9 & 0.09 & (21) & 0.07 & (21) \\
\hline 16 & 0.39 & (18) & 0.40 & (18) \\
\hline 23 & 0.21 & (16) & 0.33 & (15) \\
\hline 30 & 0.21 & (13) & 0.32 & (13) \\
\hline 37 & -0.15 & (8) & 0.08 & (8) \\
\hline
\end{tabular}

Table I Correlation coefficients ${ }^{1}$ between total coma score, motor responsiveness score, and ODmax

'Spearman's rank correlation coefficient; ${ }^{*} P<0.02 ;{ }^{* *} P<0.01$; $* * * \mathrm{P}<0.001$.

Theoretically it is possible that the significant correlations between the parameters of consciousness (total coma and motor responsiveness score) and ODmax (table I) were actually spurious relations brought about by correlations between platelet count and ODmax or between platelet count and parameters of consciousness. In order to exclude this 

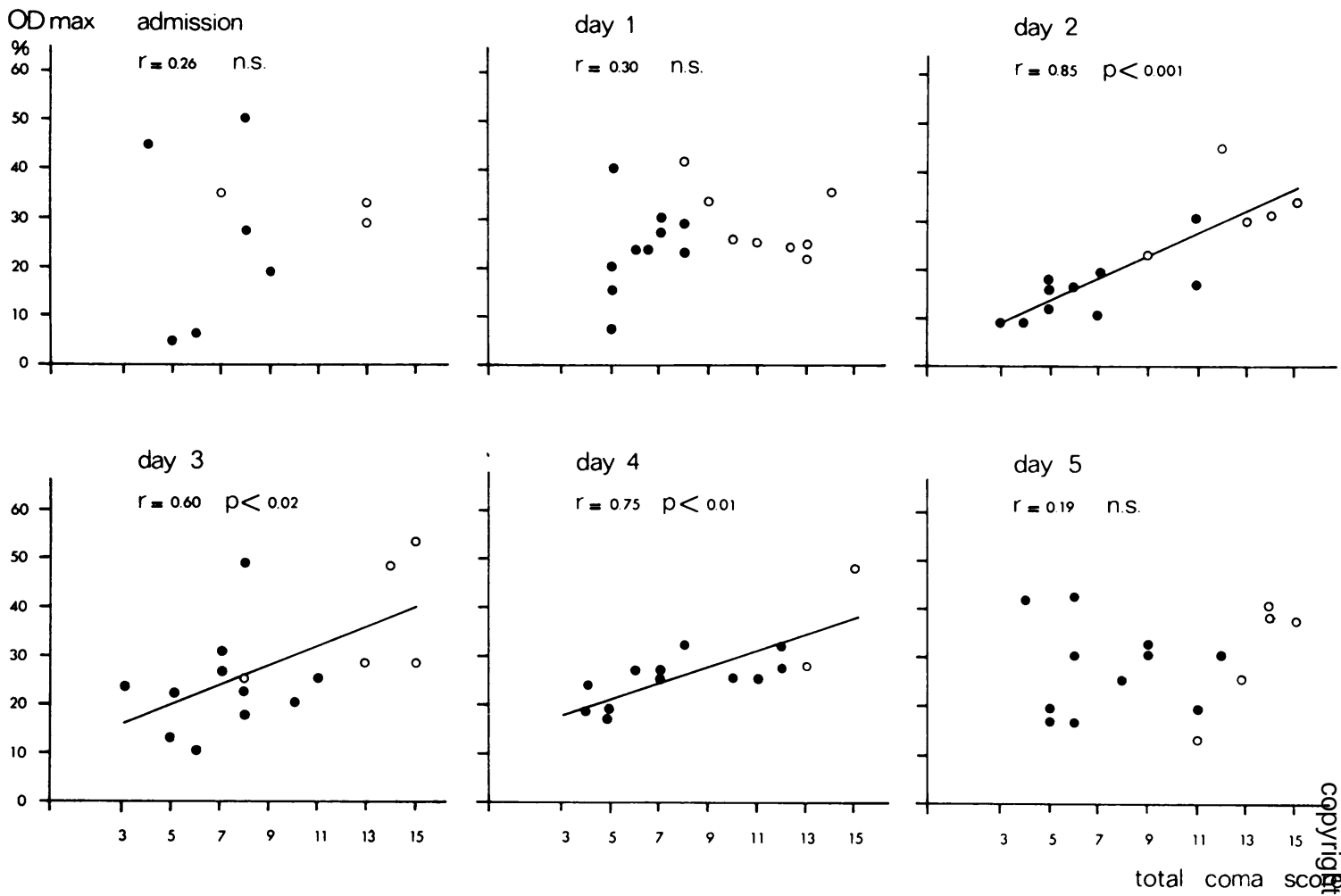

Fig 4 Spearman's rank correlation and linear regression lines between total coma score and ODmax on the first five post-traumatic days separately.

group II; $\bigcirc$ group III.

\begin{tabular}{lccc}
\hline Day & $\begin{array}{l}\text { Platelet Count } \\
\text { VODmax }\end{array}$ & $\begin{array}{l}\text { Platelet Count } \\
\text { v Total Coma Score }\end{array}$ & $\begin{array}{l}\text { Platelet Count } \\
\text { M Motor Responsiveness Score }\end{array}$ \\
\hline Admission & $-0.19(8)$ & $0.33(13)$ & $0.29(13)$ \\
1 & $0.54^{*}(15)$ & $0.11(19)$ & $0.06(19)$ \\
2 & $-0.30(14)$ & $-0.19(22)$ & $0.12(22)$ \\
3 & $0.41(16)$ & $0.25(21)$ & $0.22(21)$ \\
4 & $0.51(13)$ & $0.39(21)$ & $0.33(21)$ \\
5 & $-0.41(9)$ & $0.56(14)$ & $0.61^{*}(14)$ \\
\hline
\end{tabular}

Table II Correlation coefficients ${ }^{1}$ between platelet count, ODmax, total coma score, and motor responsiveness score

${ }^{1}$ Spearman's rank correlation coefficient; ${ }^{*} \mathrm{P}<0.05$.

possibility correlation coefficients were sought between platelet count and ODmax as well as between platelet count and parameters of consciousness. Table II shows that on days 1 and 5 scattered significant correlations $(P<0.05)$ were present between these parameters. Therefore it is improbable that the significant correlations between parameters of consciousness and ODmax on days 2,3 , and 4 were caused by platelet count fluctuations.

\section{Discussion}

In this study we have shown that after severe head injury with longstanding loss of consciousness platelet aggregability was considerably decreased. In addition we assessed the relation between the state of consciousness of the patient and platelet aggregability in the first days after head injury. A significant correlation was also found between motor re- 
sponsiveness and platelet function. The motor responsiveness component of the coma score (Teasdale and Jennett, 1974) represents increasing brainstem dysfunction (Plum and Posner, 1972) as the patient obeys commands, localizes stimuli, and shows normal flexion, abnormal flexion, extensor spasms or no response on pain stimuli respectively. Therefore we tend to relate inhibition of platelet function to brainstem dysfunction.

In the acute phase after cerebrovascular accidents platelet inhibition has been described (Danta, 1973). The phagocytizing capacity of the neutrophil granulocyte, which is in many characteristics similar to platelet phagocytosis (Mustard and Packham, 1968; Stormorken, 1969), is diminished in comparable situations as described here: after brain trauma and anoxia (Dodsworth and Harris, 1971) and after head injury (van Woerkom et al, 1973) depressed adhesion and phagocytosis have been reported. Similar phenomena have also been found during general anaesthesia and operations in platelets (O'Brien et al, 1971) and granulocytes (Löfström and Schildt, 1974).

Up till now no explanation has been given for these-reversible-functional abnormalities in the leucocyte and platelet. It seems that a relation between platelet dysfunction and coma may imply a relation between platelet function and mesencephalic and diencephalic activity, by which the comatose condition is influenced (Plum and Posner, 1972). Previously we found a relation between the comatose condition and the concentration of degradation products in the cerebrospinal fluid (CSF) of cerebral serotonin: unconscious patients showed higher 5-hydroxyindoleacetic acid (5-HIAA) concentrations in the lumbar CSF compared to conscious patients after severe head injury (Vecht $\boldsymbol{e t}$ $a l, 1975 a)$. These findings were also encountered in patients who received repeated lumbar punctures and showed lower 5-HIAA concentrations after regaining consciousness (Vecht et al, 1975b). Serotoninproducing neurons in the brain are situated mainly in the raphe nuclei in the mesencephalon (Dahlström and Fuxe, 1965). During coma and coma-like conditions the cerebral serotonin turnover has been shown to increase (Osterholm et al, 1969; Knell et al, 1974). The activity of cerebral serotonin and other neurotransmitter substances (norepinephrine and acetylcholine in the brainstem) have been proven to influence stress, adrenal function, and corticosteroid levels (Vernikos-Danellis et al, 1973). Cerebral serotonin could have an important function in regulating peripheral sympathetic and parasympathetic activity (Bogdanski et al, 1958; Garattini and Valzelli, 1965). After head injury high catecholamine blood concentrations have been reported
(Grashchenkov et al, 1965). Therefore we think that these increased concentrations may act upon platelet $\beta$-adrenergic receptors which induce via their action on adenylate cyclase a rise in intracellular cyclic 3', 5'-adenosine monophosphate (cAMP) (Haslam, 1973; Mannucci et al, 1974). High cAMP levels coincide with a diminished platelet aggregability (Salzman et al, 1970).

Moreover, high acetylcholine levels have been observed following head injury (Grashchenkov et al, 1965). Acetylcholine esterase is present in platelets, and acetylcholine esterase-inhibitors have been shown to inhibit platelet function (Saba and Mason, 1970).

In conclusion, we suggest that during the acute comatose state after head injury a brainstem dysfunction exists which gives rise to raised neurohumoral levels (catecholamines and acetylcholine) in the circulating blood. These increased concentrations of neurohumoral substances may be responsible for a decrease in platelet function.

This study was supported in part by a grant from the Netherlands Ministry of Public Health. Mrs J. Ophof-Post, Miss B. Hansen, Miss R. Stienstra, and Miss W. Postma gave technical help and Mrs A. Tuin-Willems gave secretarial assistance.

\section{References}

Bayer, S. M. and McCoy, E. E. (1974). A comparison of the serotonin and ATP content in platelets from subjects with Down's syndrome. Biochem. Med., 9, 225-232.

Bogdanski, D. F., Weissbach, H., and Udenfriend, S. (1958). Pharmacological studies with the serotonin precursor, 5-hydroxytryptophan. J. Pharmacol.exp.Ther., 122, 182-194.

Born, G. V. R. (1962). Aggregation of blood platelets by adenosine diphosphate and its reversal. Nature (Lond.), 194, 927-930.

Caspary, E. A., Prineas, J., Miller, H., and Field, E. J. (1965). Platelet stickiness in multiple sclerosis. Lancet, 2, 11081109.

Dahlström, A. and Fuxe, K. (1965). Evidence for the existence of monoamine-containing neurons in the central nervous system. I. Demonstrations of monoamines in the cell bodies of brain stem neurons. Acta physiol. scand., 62 , Suppl. 232, 1-55.

Danta, G. (1973). Platelet aggregation in patients with cerebral vascular disease and in control subjects. Thrombos. Diathes. haemorrh. (Stuttg.), 29, 730-732.

Dodsworth, H. and Harris, R. (1971). Granulocyte function in patients with brain damage and anoxia. Acta haemat. (Basel), 45, 350-355.

Garattini, S. and Valzelli, L. (1965). Serotonin. Elsevier, Amsterdam.

Goodnight, S. H., Kenoyer, G., Rapaport, S. I., Patch, M. J., Lee, J. A., and Kurze, T. (1974). Defibrination after braintissue destruction. New Engl. J. Med., 290, 1043-1047.

Grashchenkov, N. I., Boeva, E. H., Irger, J. M., Kassil G N., Kamanetskaya, B. I., and Fishman, M. N. (1965). Clinical and pathophysiological analysis of acute closed craniocerebral injury. In Proceedings of the 3rd Inter- 
national Congress of Neurological Surgery, 1965, pp. 119. 125. Excerpta Medica, Amsterdam.

Haslam, R. J. (1973). Interactions of the pharmacological receptors of blood platelets with adenylate cyclase. Ser. Haematol., 6, 333-350.

Jennett, B. and Plum, F. (1972). Persistent vegetative state after brain damage. Lancet, 1, 734-737.

Knell, A. J., Davidson, A. R., Williams, R., Kantamameni, B. D., and Curzon, G. (1974). Dopamine and serotonin metabolism in hepatic encephalopathy. Brit. med. J., 1, 549-551.

Löfström, B. and Schildt, B. (1974). Reticuloendothelial function under general anaesthesia. Acta anaesth. scand., 18, 34-40.

Mannucci, P. M., Vechietti, P., and Mannucci, L. (1974). Cyclic AMP and inhibition of platelet aggregation. In Platelet Aggregation and Drugs, edited by L. Caprino and E. C. Rossi, pp. 107-128. Academic Press, London and New York.

Mustard, J. F. and Packham, M. A. (1968). Platelet phagocytosis. Ser. Haematol., 1(2), 168-184.

O'Brien, J. R., Etherington, M., and Jamieson, S. (1971). Refractory state of platelet aggregation with major operations. Lancei, 2, 741-743.

Osterholm, J. L., Bell, J., Meyer, R., and Pyenson, J. (1969). Experimental effects of free serotonin on the brain and its relation to brain injury. J. Neurosurg., 31, 408-421.

Plum, F. and Posner, J. B. (1972). The Diagnosis of Stupor and Coma. F. A. Davis, Philadelphia.

Preston, F. E., Malia, R. G., Sworn, M. J., Timperley, W. R., and Blackburn, E. K. (1974). Disseminated intravascular coagulation as a consequence of cerebral damage. $J$. Neurol. Neurosurg. Psychiat., 37, 241-248.

Saba, S. R. and Mason, R. G. (1970). Acetylcholine, cholin- 을 esterase activity and the aggregability of human platelets. Proc. exp. biol. Med., 135, 104-107.

Salzman, E. W., Rubino, E. B., and Sims, R. V. (1970). Cyclic 3', 5'-adenosine monophosphate in human blood platelets. III. The role of cyclic AMP in platelet aggregation. Ser. Haematol., 3(4), 100-113.

Stormorken, H. (1969). The platelet release reaction. Its general aspects and relation to phagocytosis/pinocytosis. Scand. J. clin. Lab. Invest., Suppl. 107, pp. 115-120.

Teasdale, G. and Jennett, B. (1974). Assessment of coma and impaired consciousness. Lancet, 2, 81-83.

Vecht, C. J. and Smit Sibinga, C. T. (1974). Head injury and defibrination. (Letter). Lancet, $2,905$.

Vecht, C. J., van Woerkom, T., Teelken, A. W., and Minderhoud, J. M. (1975a). 5-Hydroxyindoleacetic acid (5-HIAA) levels in the cerebrospinal fluid in consciousness and unconsciousness after head injury. Life Sciences, 16, 1179-1186.

Vecht, C. J., van Woerkom, T., Teelken, A. W., and $\infty$ Minderhoud, J. M. (1975b). HVA and 5-HIAA CSF $\vec{A}$ levels and the state of consciousness after head injury. Archiv. Neurol. (In press).

Vernikos-Danellis, J., Berger, P., and Barchas, J. D. (1973). Brain serotonin and pituitary-adrenal function. Prog. Brain Res., 39, 301.

van Woerkom, T., Teelken, A. W., and Minderhoud, J. M. (1973). Impairment of phagocytosis by granulocytes in brain-damaged patients. (Letter). Lancet, 2, 97. 